\title{
Saccharin analysis in pharmaceutical and cosmetic preparations by derivative ultraviolet spectrophotometry
}

\author{
Cristina Duarte Vianna-Soares ${ }^{1 *}$, Jorge Luiz Seferin Martins ${ }^{2}$
}

${ }^{1}$ Departamento de Produtos Farmacêuticos, Faculdade de Farmácia, Universidade Federal de Minas Gerais, ${ }^{2}$ Departamento de Farmácia, Faculdade de Ciências Farmacêuticas, Universidade de São Paulo

*Correspondence:

C.D. Vianna-Soares

Faculdade de Farmácia

Universidade Federal de Minas Gerais Av. Olegário Maciel, 2360 30112-180 - Belo Horizonte - MG

E-mail: cviannas@farmacia.ufmg.br
Saccharin, a synthetic sweetener constituent of several pharmaceutical and cosmetic preparations, is analyzed qualitatively and quantitatively in the presence of interferences like active ingredients and excipients. A derivative ultraviolet spectrophotometric method employing the second and the fourth orders was used. The calibration data obtained were satisfactory, with a relative precision range of $0.53 \%-0.72 \%$, and linearity between 0.9998-0.9999. The recovery test results for the toothgel sample ranged between $97.80 \%$ and $104.95 \%$ in the second order of derivative and between $98.04 \%$ and $101.32 \%$ in the fourth derivative, respectively, using zero-peak (ZP) and peak-peak (PP) methods. The suspension sample showed values between $97.35 \%$ and $104.72 \%$ in the second derivative and between $95.94 \%$ to $104.41 \%$ in the fourth derivative, respectively, employing the zeropeak (ZP) and peak-peak (PP) methods. The proposed method showed precision, accuracy and simplicity.

\section{INTRODUCTION}

From the scientific and technical standpoint the quality control of excipients implies in the verification of specifications that prove the uniformity of their chemical and physical-chemical characteristics. Nevertheless, technological aspects should also guarantee the quality and safety for the employment of the finished product as a whole, comprising active and inactive ingredients. The excipients, however, considered inert under the therapeutic point of view, do not always offer the purity criteria necessary to the pharmaceutical and food usage.

Lately in Europe, there has been an increasing interest on the quantitative determination of excipients in the formulations. In Belgium, as for instance, such analyses are routinely performed, nonetheless, in case the excipient determination is not achievable its identification should, at least, be performed. In Brazil, where that is not yet a routine, the main problems reside on the regulatory and financial aspect. According to the Brazilian legislation, the analyses of excipients are not mandatory for quality control purposes; however, the active ingredients' analyses are. In addition, the high cost involved with these analyses do not stimulate the manufacturers to pursue them. The multiplicity of excipients in formulations, as well as their different quality in the market hinders the application of common analytical procedures and consequently increase the expenses of the total analysis of a product. 
Saccharin, particularly, an artificial sweetener present in several pharmaceutical preparations, showed us much interest due to the fact that it constitutes an excipient when utilized in small concentrations, and also an active ingredient when utilized in greater concentrations, as in table artificial sweeteners (Vianna-Soares, Martins, 1995).

Fahlberg and Remsen (1879) reported the synthesis of saccharin (1,2-benzisothiazol-3(2H)-one 1,1-dioxide) (Fabiani, 1981; Merck, 1996). Even though it was widely investigated concerning to toxicological effects, its consumption enhanced greatly in the European west, mainly during the first and second world wars when the sugar cane was not available. Nowadays, Europeans consume less saccharin per capita than North Americans (Arnold, 1980).

Studies showed later that saccharin is a non-caloric sweetening agent and a non-cariogenic substance (Brandon, Sadler, 1985; Hill, Flaitz, Frost, 1988) opposed to sucrose, which is generally used in liquid preparations such as syrups, oral solutions, drops, suspensions. Saccharin as sucrose substitute has increased in pharmaceutical dosage forms intended for internal administration like those preparations cited as well as for food and for drink purposes. Last but not least, as mouth cleansing products as mouthwash solutions and dentifrices in the form of pastes or gels, do contain saccharin as excipient. The sweetener is, therefore, present in cosmetic preparations, as these products are classified under the Brazilian legislation.

The sweetener chemical structure is shown in Figure 1. It presents a very low absorptivity, and because it is utilized in very small concentrations as an excipient it becomes very difficult and laborious to determine saccharin in a quantitative way.

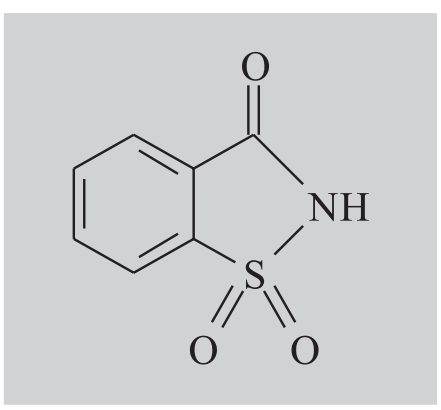

FIGURE 1 - Chemical structure of saccharin (1,2benzisothiazol-3(2H)-one 1,1-dioxide). Molar mass 183.19 .

In the literature, several reviews have been reported and many methods proposed for the identification and quantitation of saccharin, as follows:
- thin layer chromatography (Auricchio, 1987, 1989; Guven et al., 1984) and paper chromatography (Ichibagasse, Kojima, 1962; Mitchell, 1955) were described for qualitative analysis mainly in food, beverages, artificial sweeteners and pharmaceutical preparations; high performance liquid chromatography (Hann, Gilkison, 1987; Leunberger, Gauch, Baumgartner, 1979; Szokolay, 1980) and gas chromatography (Kacprzak, 1978; Riggin, Kinzer, 1983) show application in beverages, pharmaceutical preparations and food;

- visible spectrophotometry of saccharin involving the formation of colored compounds at $651 \mathrm{~nm}$ (Betalgy, 1974), 630 nm; (Hernandez-Cordoba, Lopez-Garcia, Sanches-Pedreno, 1985), $544 \mathrm{~nm}$ (Guven et al., 1984) and $685 \mathrm{~nm}$ (Ramappa, Nayak, 1983) are described. Zero order ultraviolet spectrophotometry was applied for saccharin determination at $244 \mathrm{~nm}$ (Hussein, Jacin, Rodriguez, 1976) in chewing gums. First order derivative ultraviolet spectrophotometry was applied in nickel electroplating solutions (Fix, Pollack, 1980) and in artificial sweeteners (Korany, 1983). The second order derivative ultraviolet spectrophotometry for determination of saccharin was employed in artificial sweeteners (Benfenati, 1989; Paseiro Losada, Simal Lozano, Simal Gándara, 1989).

- other techniques outlined for saccharin determination are volumetry in aqueous solution (British, 1988; Garrat, 1964; Hager, 1950; United, 2002), in non-aqueous solution(British, 1988; Vyas, Kharat, 1988) polarography (Neiman, 1955) and gravimetry (Markus, 1973). However, many of them lack selectivity and sensitivity.

Because saccharin appears in very low concentrations in pharmaceutical and cosmetic preparations and presents a very low absorptivity feature, this brings out a problem for its quantitative analysis in the presence of other excipients and active ingredients, if the method used does not show good precision or specificity.

The proposed method describes the application of derivative ultraviolet spectrophotometry in an oral suspension liquid dosage form and in a cosmetic gel dosage form.

\section{MATERIALS AND METHODS}

\section{Chemicals and solutions}

Saccharin standard solutions containing $40.0 \mu \mathrm{g} . \mathrm{mL}^{-1}$ and $50.0 \mu \mathrm{g} . \mathrm{mL}^{-1}$ were prepared in $0.1 \mathrm{M}$ 
sodium hydroxide solution. Other reagents used were 3.0 $\mathrm{M}$ hydrochloride acid solution and chloroform:ethanol $(9+1)$. A commercial cosmetic sample, a dentifrice in the form of gel containing sodium saccharin, was purchased in the local commerce. The gel sample showed a label claim of $0.21 \% \mathrm{w} / \mathrm{w}$ saccharin. Also a simulated $2.5 \% \mathrm{w} / \mathrm{v}$ fenitoin oral suspension preparation containing $0.2 \% \mathrm{w} / \mathrm{v}$ sodium saccharin was manufactured in-house and used as a pharmaceutical sample. Its exact placebo formulation, containing no saccharin was also prepared in the same manner.

\section{Apparatus}

The ultraviolet/visible BECKMAN DU 70 spectrophotometer with $1 \mathrm{~cm}$-quartz cuvettes, attached to the printer EPSON FX/850 were used. The instrument slit width was $2 \mathrm{~nm}$ and scan-speed range was $60-2400 \mathrm{~nm} \cdot \mathrm{min}^{-1}$. The THORNTON T-14 water bath and FANEM EXCELSA 3 centrifuge were used as auxiliary instruments.

\section{Methods}

The working instrumental conditions were described in previous work (Vianna-Soares, Martins, 1995) as follows: Two orders of differentiation, second and fourth, were selected; the differential wavelength was 4 $\mathrm{nm}$ for the second derivative and $12 \mathrm{~nm}$ for the fourth derivative; the scan-speed utilized was $120 \mathrm{~nm} \cdot \mathrm{min}^{-1}$ and the ordinate axis for both orders of differentiation was \pm 0.025; the wavelength range was 240.0-320.0 $\pm 0.5 \mathrm{~nm}$ and the noise attenuation employed was 11 , as shown in the equipment; the selected modes of measurements were zero-peak (ZP) and peak-peak (PP).

\section{Preparation of the calibration graphs}

Standard stock solution was prepared by accurately weighing $100 \mathrm{mg}$ of saccharin and transferring to a 100 $\mathrm{mL}$ volumetric flask. Volume was filled up with $0.1 \mathrm{M}$ sodium hydroxide solution. Aliquots of $2.0 \mathrm{~mL}$ and 5.0 $\mathrm{mL}$ were transferred to a $50 \mathrm{~mL}$ and a $100 \mathrm{~mL}$ volumetric flask, respectively, to make up analytical diluted standard concentrations of $40 \mathrm{mg} \cdot \mathrm{mL}^{-1}$ and $50 \mathrm{mg} \cdot \mathrm{mL}^{-1}$ of saccharin. The former diluted standard solution was used for the spectra overlay with toothgel cosmetic sample, and the later was used for the spectra overlay with the oral suspension pharmaceutical sample.

The utilized derivative spectrophotometric methods were standardized in the concentration interval of 28.0$98.0 \mathrm{mg} \cdot \mathrm{mL}^{-1}$ in $0.1 \mathrm{M}$ sodium hydroxide solution after verification of the linear range in the zero order spectrophotometry through Ringbom curve in the same solvent solution. The results obtained were statistically analyzed by linear regression, using the least squares method (Davis, Thompson, Pardue, 1978).

\section{Preparation of the cosmetic sample}

Accurately weighed equivalent amount of $25 \mathrm{mg}$ saccharin were transferred to a $50 \mathrm{~mL}$ volumetric flask, dissolved into distilled water and the solution centrifuged for 20 minutes at a speed of $2500 \mathrm{rpm}$. A $20.0 \mathrm{~mL}$ aliquot was taken from the supernatant, acidified with $2 \mathrm{~mL} 3.0 \mathrm{M}$ hydrochloric acid and extracted in a separation funnel with $100 \mathrm{~mL}$ organic immiscible solvent, chloroform:ethanol $(9+1)$, in 4 portions of $40,20,20$ and $20 \mathrm{~mL}$. The extracts gathered together were residue dried and dissolved with 10 $\mathrm{mL}$ of $0.1 \mathrm{M}$ sodium hydroxide solution into a $25 \mathrm{~mL}$ volumetric flask. The volume was completed with distilled water. Aliquots of $1.0 \mathrm{~mL}$ were transferred to $10 \mathrm{~mL}$ volumetric flasks in $0.1 \mathrm{M}$ sodium hydroxide solution and submitted to derivative ultraviolet spectral analysis. Toothgel sample analytical concentration was $40 \mathrm{mg} \cdot \mathrm{mL}^{-1}$ of saccharin.

\section{Preparation of the pharmaceutical sample}

For the pharmaceutical preparation, an aliquot of $15.0 \mathrm{~mL}$ was transferred to a $50 \mathrm{~mL}$ volumetric flask and the volume completed with distilled water. An aliquot of $15.0 \mathrm{~mL}$ of the diluted suspension was extracted in a separation funnel with $100 \mathrm{~mL}$ organic immiscible solvent, which thereafter, was discarded. The aqueous extract was transferred into a $50 \mathrm{~mL}$ volumetric flask and the volume completed with $0.1 \mathrm{M}$ sodium hydroxide solution. Further dilution of $3.0 \mathrm{~mL}$ to $10 \mathrm{~mL}$ volumetric flask was obtained. Replicates of this solution, with an analytical concentration of $48.2 \mathrm{mg} . \mathrm{mL}^{-1}$ were analyzed by derivative ultraviolet spectrophotometry. Placebo sample was treated for dilution and extraction equivalently.

\section{RESULTS AND DISCUSSION}

The standardized linear concentration range, 28.0$98.0 \mathrm{mg} . \mathrm{mL}^{-1}$ in $0.1 \mathrm{M}$ sodium hydroxide solution, found to obey Lambert-Beer's Law in zero order ultraviolet spectrophotometry, was also applicable to the derivative spectrophotometry in the wavelength range of 240.0$320.0 \mathrm{~nm}$. Second and fourth orders of differentiation, which showed a good curve profile of saccharin under the present conditions, were selected for measurements based 
upon previous derivative fundamentals described by Fell (1978) and Shibatta, Furukawa, Goto (1973).

The relative precision $(\% R S D)$ of the standardized method varied between $0.53 \%-0.72 \%$ and linearity (correlation coefficient, $r$ ) varied between 0.9998-0.9999 in the concentration interval of $28.0-98.0 \mathrm{mg} . \mathrm{mL}^{-1}$ in 0.1 $\mathrm{M}$ sodium hydroxide solution. These values indicate a pretty reasonable and acceptable error, below $2 \%$, as well as a good correlation between the measurement modes of the method and the analyte concentration.

The derivative curve features can be visualized in Figure 2, where zero-peak (ZP) is measured by the peak to baseline amplitude and peak-peak (PP) is measured by
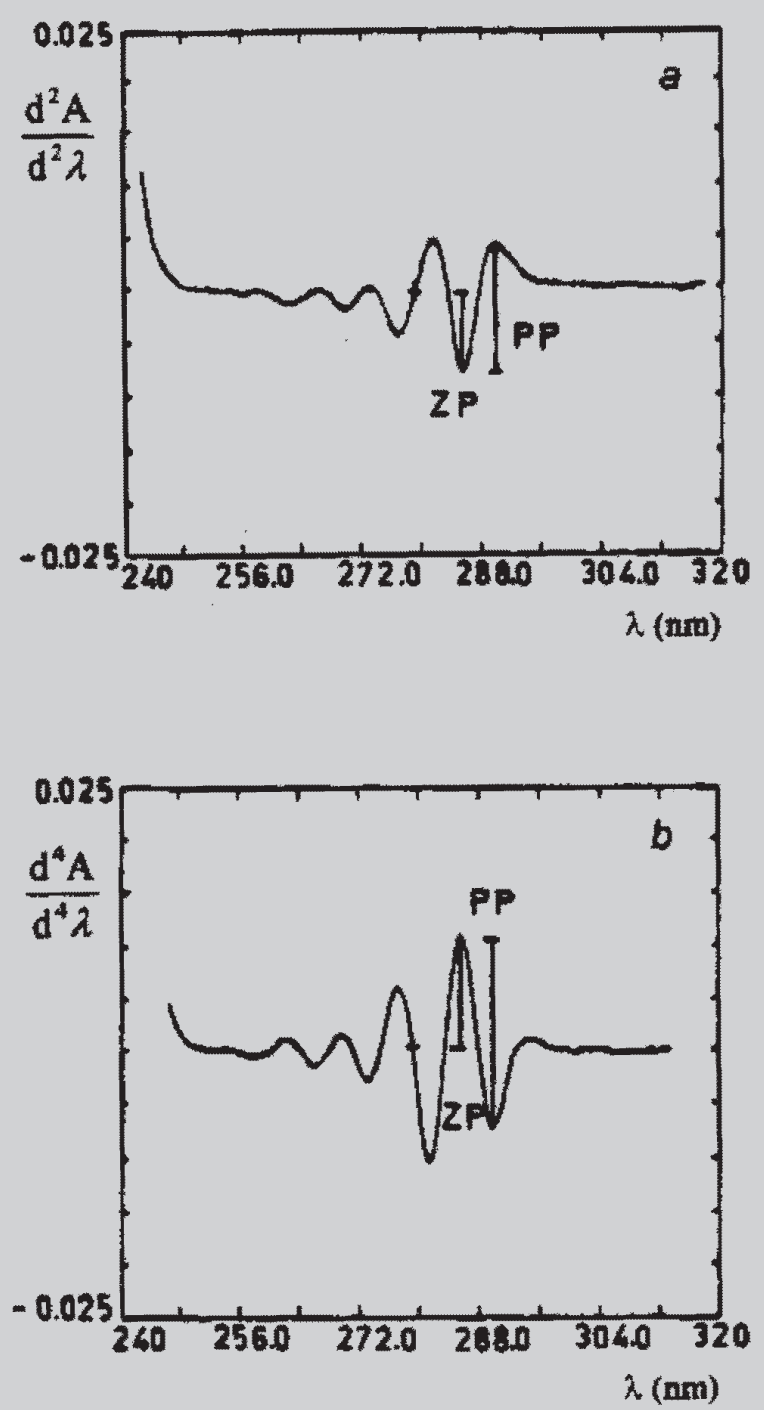

FIGURE 2 - Second (a) and fourth (b) derivative ultraviolet spectra of standard saccharin, in $0.1 \mathrm{M}$ sodium hydroxide solution at concentration of $50.0 \mu \mathrm{g} \cdot \mathrm{mL}^{-1}$. peak to peak amplitude. The ZP and PP methods employed for second order (a) and fourth order (b) quantitative determinations of standard saccharin presented a good correlation for quantitative analysis.

While it is acknowledged that analytical background absorption of pharmaceutical preparations accounts for either the presence of inactive ingredients resulting in great interferences or, high drug absorptivity resulting in overlapping curves, the method was applied in cosmetic and pharmaceutical samples, toothgel and oral suspension, to prove the ability of predicting saccharin determinations.

It is important to note that interferences usually caused by other excipients or active ingredients may be partially or totally eliminated with sample pre-treatment or separations. In this study centrifugation at $2500 \mathrm{rpm}$ for 20 minutes, and extraction with immiscible solvent were carried out for the toothgel and the oral suspension samples, respectively, with the purpose of eliminating gross interferences and facilitating the analysis.

Figure $3 a$ demonstrates that the conventional zero order ultraviolet spectra of saccharin (Clarke, 1986) from pre-treated toothgel sample in $0.1 \mathrm{M}$ sodium hydroxide solution is still markedly influenced by the presence of excipients and/or active ingredients. Observing the second (b) and fourth (c) orders of derivatives spectra in Figure 3, one can notice that the background interference is completely eliminated, as we verify the coincident overlay of standard solution (P) and the toothgel sample (A) spectra. Although the placebo sample is not shown along with the spectra due to unavailability from the manufacturer, one can verify that the combined procedure of sample pretreatment and differentiation is capable of eliminating the high background placebo absorption. The same cannot be stated true for the pre-treatment of the toothgel sample solely.

In Figure $4 a$, the extracted oral suspension sample (A) already shows a great elimination of background absorption compared to the absorption obtained with the suspension simple dilution only (results not shown), however, the placebo sample (C) still biases the analysis with a low absorption even after the extraction procedure.

In Figure $4 b$ and $c$, the spectra differentiation leads to the evident elimination of placebo interference as it is observed from the flat baselines achieved. Despite that, the exact superimposition of the standard $(\mathrm{P})$ and oral suspension sample (A) solutions in the differentiated spectra does not occur due to the lower saccharin concentration in the oral suspension sample (A), compared to saccharin concentration in the standard solution $(\mathrm{P})$. The suspension dosage form itself imposes 

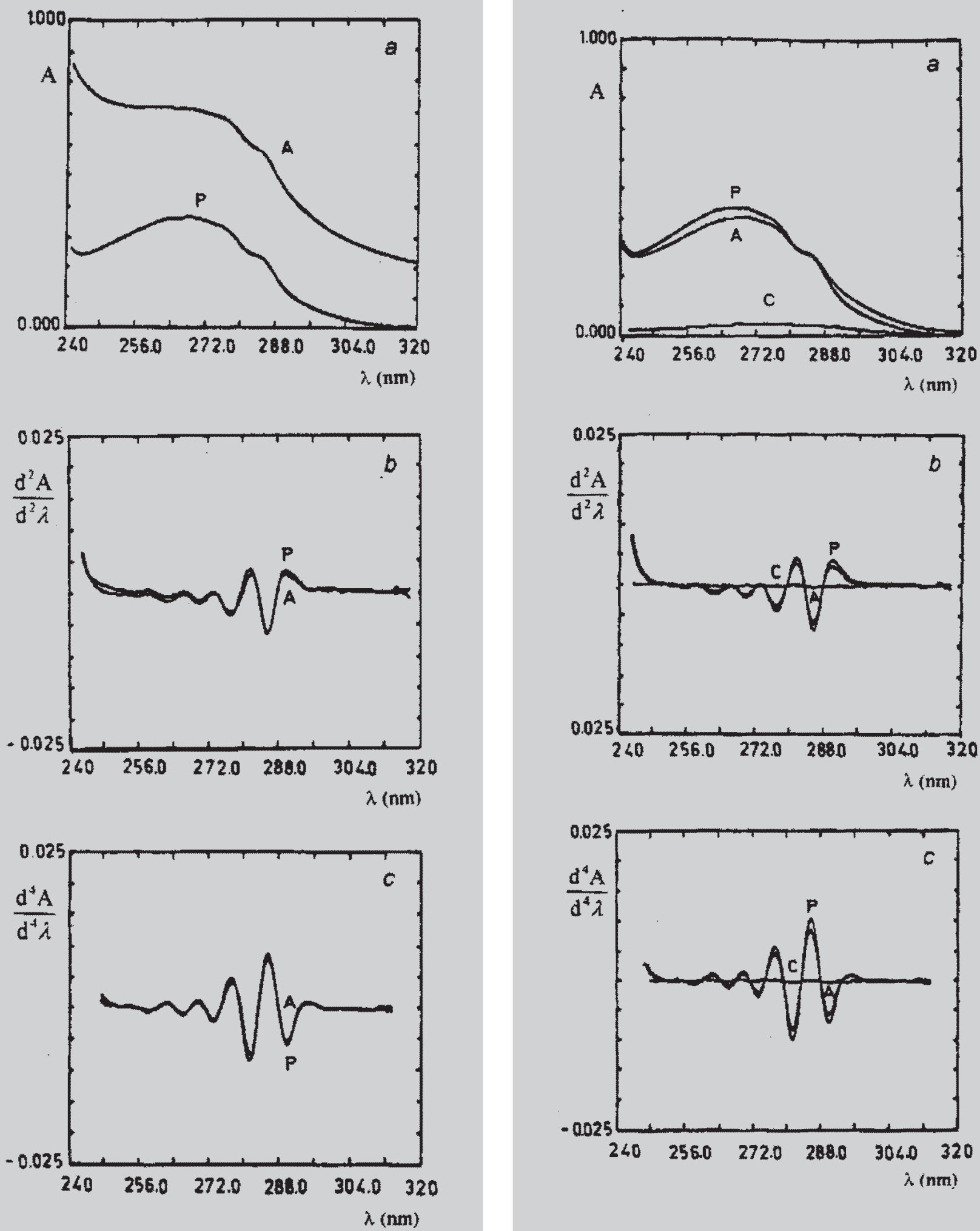

FIGURE 3 - Zero (a), second (b) and fourth (c) derivative ultraviolet spectra of toothgel sample (A) and standard saccharin solution $(\mathrm{P})$, in $0.1 \mathrm{M}$ sodium hydroxide solution at concentration of $40.0 \mu \mathrm{g} \cdot \mathrm{mL}^{-1}$.

FIGURE 4 - Zero (a), second (b) and fourth (c) derivative ultraviolet spectra of oral suspension sample (A) at a concentration of $48.2 \mathrm{mg} \cdot \mathrm{mL}^{-1}$, standard saccharin solution at concentration of $50.0 \mu \mathrm{g} \cdot \mathrm{mL}^{-1}(\mathrm{P})$ and suspension placebo $(\mathrm{C})$, in $0.1 \mathrm{M}$ sodium hydroxide solution. 
non-coincidental analytical concentration in the process, meanwhile, the same does not happen with saccharin standard solution, readily prepared from a solid reagent.

The method however is precise, showing coefficients of variation $(\% \mathrm{CV})$ in an acceptable range. Application of the second derivative method to the samples resulted in satisfactorily precise values of coefficients of variation. The zero-peak and the peak-peak methods presented a precision of $1.60 \%$ and $1.22 \%$ for toothgel and, $1.39 \%$ and $1.57 \%$ for the oral suspension respectively. Fourth derivative method yielded coefficients of variation of $0.97 \%$ and $0.69 \%$ for toothgel, $0.92 \%$ and $1.00 \%$ for oral suspension, for the zero-peak and peak-peak methods respectively. Precision results were calculated using ten duplicate determinations of the sample solutions around the central point $\left(50.0 \mathrm{mg} \cdot \mathrm{mL}^{-1}\right)$ of the linear interval.

The recovery results (Table I) were obtained according to the methods of standards addition (AOAC, 1990). They ranged from $97.80 \%$ to $104.95 \%$ in the second derivative and from $98.04 \%$ to $101.32 \%$ in the fourth derivative, respectively, for zero-peak and peak-peak methods in the toothgel sample. In the oral suspension sample the recovery values ranged from $97.35 \%$ to $104.72 \%$ in the second derivative and from $95.94 \%$ to $104.41 \%$ in the fourth derivative, respectively, for zeropeak and peak-peak methods. The method accuracy was considered to be satisfactory as the values fell in between $95.0-105.0 \%$ of the spiked amount in the samples.

\section{CONCLUSIONS}

Saccharin can easily be quantitatively determined in pharmaceutical and cosmetic preparations in presence of excipients and active ingredients, by precise and accurate second or fourth order derivative ultraviolet spectrophotometry.

The derivative ultraviolet method may also be useful for saccharin determination in foods when necessary suitable pre-treatment, if required, is executed to help eliminate or diminish gross interferences.

The feasible application of derivative spectrophotometry characterizes this method as a quick performance, due to the easy maneuverability and the low cost of reagents involved. It also constitutes a simple, useful and

TABLE I - Percentage recovery results* for commercial toothgel and simulated oral suspension samples

\begin{tabular}{|c|c|c|c|c|c|}
\hline \multicolumn{6}{|c|}{ SECOND DERIVATIVE } \\
\hline Sample & Added $\left(\mu \mathrm{g} \cdot \mathrm{mL}^{-1}\right)$ & \multicolumn{2}{|c|}{ Found $\left(\mu \mathrm{g} \cdot \mathrm{mL}^{-1}\right)$} & \multicolumn{2}{|c|}{ Recovery \% } \\
\hline & & $\mathrm{ZP}$ & PP & $\mathrm{ZP}$ & PP \\
\hline Toothgel & $\begin{array}{r}8.0 \\
16.0 \\
24.0 \\
32.0\end{array}$ & $\begin{array}{r}7.93 \\
16.53 \\
23.47 \\
32.73\end{array}$ & $\begin{array}{r}8.34 \\
16.68 \\
24.17 \\
33.58\end{array}$ & $\begin{array}{r}99.17 \\
103.31 \\
97.80 \\
102.27\end{array}$ & $\begin{array}{l}104.28 \\
104.28 \\
100.71 \\
104.95\end{array}$ \\
\hline $\begin{array}{l}\text { Oral } \\
\text { Suspension }\end{array}$ & $\begin{array}{r}5.0 \\
10.0 \\
15.0 \\
20.0\end{array}$ & $\begin{array}{r}4.88 \\
10.46 \\
15.34 \\
20.92\end{array}$ & $\begin{array}{r}4.87 \\
10.39 \\
15.71 \\
20.80\end{array}$ & $\begin{array}{r}97.68 \\
104.60 \\
102.28 \\
104.60\end{array}$ & $\begin{array}{r}97.35 \\
103.98 \\
104.72 \\
103.98\end{array}$ \\
\hline \multicolumn{6}{|c|}{ FOURTH DERIVATIVE } \\
\hline & & $\mathrm{ZP}$ & PP & $\mathrm{ZP}$ & PP \\
\hline Toothgel & $\begin{array}{r}8.0 \\
16.0 \\
24.0 \\
32.0\end{array}$ & $\begin{array}{r}7.99 \\
15.99 \\
23.53 \\
31.99\end{array}$ & $\begin{array}{r}7.86 \\
16.14 \\
24.14 \\
32.42\end{array}$ & $\begin{array}{l}99.99 \\
99.99 \\
98.04 \\
99.99\end{array}$ & $\begin{array}{r}98.25 \\
100.88 \\
100.58 \\
101.32\end{array}$ \\
\hline $\begin{array}{l}\text { Oral } \\
\text { Suspension }\end{array}$ & $\begin{array}{r}5.0 \\
10.0 \\
15.0 \\
20.0\end{array}$ & $\begin{array}{r}4.88 \\
9.76 \\
14.39 \\
20.00\end{array}$ & $\begin{array}{r}5.15 \\
10.44 \\
15.59 \\
20.74\end{array}$ & $\begin{array}{r}97.56 \\
97.56 \\
95.94 \\
100.00\end{array}$ & $\begin{array}{l}102.94 \\
104.41 \\
103.92 \\
103.68\end{array}$ \\
\hline
\end{tabular}

\footnotetext{
* Average of two determinations
} 
suitable method for saccharin routine quality control in cosmetic and pharmaceutical preparations, compared to more sophisticated techniques such as high performance liquid chromatography or gas chromatography.

\section{ACKNOWLEDGMENTS}

This work was possible with a CAPES/Brasilia/Brasil fellowship. The authors thank Colgate-Palmolive (Osasco/Brasil) for the kind donation of the toothgel samples.

\section{RESUMO}

\section{Análise da sacarina em preparações farmacêuticas e cosméticas por meio da espectrofotometria derivada no ultravioleta}

A sacarina, adoçante sintético constituinte de várias preparações farmacêuticas e cosméticas, foi analisada de forma qualitativa e quantitativa na presença de substâncias interferentes como princípios ativos e excipientes das formulações. Utilizou-se a espectrofotometria derivada no ultravioleta, por meio da segunda e da quarta ordens de diferenciação. Os resultados obtidos na padronização do método foram satisfatórios e mostraram precisão no intervalo de 0,53\%-0,72\%, e linearidade entre 0,99980,9999 . O teste de recuperação, aplicado na amostra gel dental situou entre $97,80 \%$ e 104,95\%, para a segunda ordem, e entre $98,04 \%$ e 101,32\%, para a quarta ordem de diferenciação, respectivamente, empregando os métodos zero-pico (ZP) and pico-pico (PP). A amostra suspensão oral mostrou valores entre $97,35 \%$ e $104,72 \%$, para a segunda ordem, e valores entre 95,94\% e 104,41\%, para a quarta ordem de diferenciação, respectivamente, empregando os métodos zero-pico (ZP) and pico-pico (PP). O método proposto mostrou ser preciso, simples e exato.

UNITERMOS. Sacarina. Espectrofotometria derivada no ultravioleta. Gel dental. Suspensão. Zero-pico. Pico-pico.

\section{REFERENCES}

ARNOLD, D. L. et al. Long-term toxicity of otoluenesulfonamide and sodium saccharin in the rat. Toxicol. Appl. Pharmacol., New York, v.52, p.113-151, 1980.

ASSOCIATION of official analytical chemists. Official methods of analysis. 15 ed. Arlington: AOAC, 1990. v. $1, \mathrm{p}$. XVII.
AURICCHIO, M. T. et al. Pesquisa de adoçantes não calóricos sintéticos em adoçante natural de Stevia rebaudiana (Bert) Bertoni. Rev. Bras. Farmacogn., São Paulo, v.2-4, p.53-61, 1987-1989.

BENFENATI, L. et al. Dosaggio spettrofotometrico in derivata seconda in prodotti farmaceutici, dietitici e cosmetici. Boll. Chim. Farm., Milano, v.128, p.18-21, 1989.

BETALGY, Y. A., RIDA, S. M., ISSA, A. Colorimetric determination of probenecid, saccharin, penicillins and some indicators using methylen blue. Pharmazie, Berlin, v.29, p.64-65, 1974.

BRANDON, M., SADLER, E. B. Sugar-free medicines. Pharm. J., London, v.234, p.824, 1985.

BRITISH pharmacopeia London: Her Majesty's Stationery Office, 1988. p.495-496.

CLARKE'S isolation and identification of drugs. 2.ed. London: Pharmaceutical Press, 1986. p.963.

DAVIS, R. B., THOMPSON, J. E., PARDUE, H. L. Characteristics of statistical parameters used to interpret least-squares results. Clin. Chem., Winston-Salem, v.24, p.611-20., 1978.

FABIANI, P. Édulcorants de synthese: saccharine et dulcine - donnés chimiques et toxicologiques. Ann. Falsif. Expert. Chim., Paris, v.74, p.273-283, 1981.

FAHLBERG, C., REMSEN, I. Uber die oxydation des orthotoluolsulfamids. Ber. Dtsch. Chem. Ges., Berlin, v.12, p.469-473, 1879.

FELL, A. F. Analysis of pharmaceutical dosage forms by second derivative ultraviolet-visible spectrophotometry. Proc. Anal. Div. Chem. Soc., London, v.15, p.260-267, 1978.

FIX, G. L., POLLACK, J. D. Determination of saccharin in watts nickel plating solutions by first derivative ultraviolet spectrometry. Anal. Chem., Washington, v.52, p.1589-1592, 1980.

GARRAT, D. C. The quantitative analysis of drugs. 3.ed. London: Chapman, 1964. p.554-555. 
GUVEN, K. C., OZOL, T, EKIZ, N., GUNERI, T. Spectrophotometric determination of sodium cyclamate and saccharin sodium with astrazone pink FG. Analyst, London, v.109, p.969-970, 1984.

HAGER, H. H. J. Tratado de farmácia prática. 3.ed. Barcelona: Editorial Labor, 1950. p.203-205.

HANN, J. T., GILKISON, I. T. Gradient liquid chromatographic method for the simultaneous determination of sweeteners, preservatives and colours in soft drinks. J. Chromatogr., Amsterdam, v.395, p.317322, 1987.

HERNANDEZ-CORDOBA, M., LOPEZ-GARCIA, I., SANCHES-PEDRENO, C. Spectrophotometric determination of saccharin in different materials by a solvent extraction method using nile blue as reagent. Talanta, London, v.32, p.325-327, 1985.

HILL, E. M., FLAITZ, C. M., FROST,. G. R. Sweetener content of common pediatric oral liquid medications. Am. J. Hosp. Pharm., Washington, v.45, p.135-142, 1988.

ICHIBAGASSE, H., KOJIMA, S. Studies on synthetic sweetening agents. I - Paper chromatography of cyclamate sodium, dulcin and saccharin sodium. Yakugaku Zashi, Tokyo, v.82, p.616-620, 1962.

HUSSEIN, M. M., JACIN, H., RODRIGUEZ, F. B. Quantitative determination of saccharin in food products by ultraviolet spectrophotometry. J. Agric. Food Chem., Washington, v.24, p.36-40, 1976.

KACPRZAK, J. L. Determination of o-toluenesulfonamide in artificial sweeteners containing saccharin. J. Assoc. Off. Anal. Chem., Washington, v.61, p.1528-1532, 1978.

KORANY, M. A. et al. Application of first derivative spectrophotometry to the determination of certain drugs in single component dosage forms. Farmaco Ed. Prat., Pavia, v.39, p.243-252, 1983.

LEUNBERGER, U., GAUCH, R., BAUMGARTNER, E. Determination of food preservatives and saccharin by high performance liquid chromatography. $J$. Chromatogr., Amsterdam, v.173, p.343-348, 1979.

MARKUS, J. R. Gravimetric determination of saccharin in cider. J. Assoc. Off. Anal. Chem., Washington, v.56, p.162-163, 1973.
MERCK index. 12.ed. Rahway: Merck, 1996. p.1430.

MITCHELL, L. C. Separation and identification of cyclohexylsulfamate, dulcin, and saccharin by paper chromatography. J. Assoc. Off. Agric. Chem., Washington, v.38, p.943-947, 1955.

NEIMAN, M. B. Polarographic determination of saccharin. J. Anal. Chem. USSR Engl. Transl., New York, v.10, p.163-167, 1955.

PASEIRO LOSADA, P., SIMAL LOZANO, J., SIMAL GÁNDARA, J. Determinación de sacarina mediante espectrofotometria UV en productos dietéticos y antiobesidad. An. Bromatol., Madrid. v.41, p.177-188, 1989.

RAMAPPA, P. G., NAYAK, A. N. Rapid spectrophotometric determination of saccharin in soft drinks and pharmaceuticals using azure B as reagent. Analyst, London, v.108, p.966-970, 1983.

RIGGIN, R. M., KINZER, G. W. Characterization of impurities in commercial lots of sodium saccharin produced by Sherwin-Williams process. I. Chemistry. Food Chem. Toxicol., Oxford, v.21, p.11-17, 1983.

SHIBATTA, S., FURUKAWA, M., GOTO, K. Dualwavelength spectrophotometry; qualitative and quantitative analysis by means of first-derivative spectra. Anal. Chim. Acta, Amsterdam, v.65, p.49-58, 1973.

SZOKOLAY, A. M. High performance liquid chromatographic determination of impurities in commercial saccharin. J. Chromatogr., Amsterdam, v.187, p.249-254, 1980 .

UNITED states pharmacopeia. 25.ed. Rockville: United States Pharmacopeial Convention, 2002. p.1545, 2610.

VIANNA-SOARES, C. D., MARTINS, J. L. S. Derivative ultraviolet spectrophotometric determination of saccharin in artificial sweeteners. Analyst, London, v.120, p.193-195, 1995.

VYAS, P. N., KHARAT, R. B. Conductimetric and enthalpimetric determination of saccharin in acetone. $J$. Indian Chem. Soc., Calcutta, v.65, p.885-886, 1988.

Recebido para publicação em 08 de agosto de 2002. 